Gut, 1989, 30, 404-405

Case report

\title{
Barrett's ulcer: cause of spontaneous oesophageal perforation
}

\author{
A J LIMBURG, E J HESSELINK, AND J H KLEIBEUKER \\ From the Departments of Gastroenterology and Surgery, University Hospital, Groningen, The Netherlands
}

SUMMARY We report two patients, who presented within six months with the classic clinical picture of 'spontaneous' oesophageal perforation, which was caused by a perforated Barrett's ulcer. These two cases underline the importance of postoperative endoscopy in ruling out intrinsic oesophageal disease as the cause of the rupture in every patient, who survives this life threatening condition.

The causes of oesophageal perforation are usually classified as traumatic, instrumental, and spontaneous with or without intrinsic oesophageal disease. 'Spontaneous or strain induced perforation, first described by Boerhaave, ${ }^{2}$ is rare and occurs during acute retching or vomiting, although such a history is not invariably present. ${ }^{3}$ Spontaneous perforation of the oesophagus may occur as a complication of primary oesophageal disease, as is well documented for carcinoma of the oesophagus. Although it has been suggested that spontaneous perforation may also be caused by benign oesophageal ulcerations,' few firm data have been presented and most series do not provide objective evidence.

This report describes two patients with the classic clinical picture of spontaneous oesophageal perforation, which was caused by a perforated Barrett's ulcer.

\section{Patient 1}

This 66 year old man was admitted with a two day history of vomiting, retrosternal pain and progressive dyspnoea. He had had a hiatal hernia with reflux oesophagitis for many years. Eight months before admission endoscopy showed two Barrett's ulcers, which almost completely healed after two months ranitidine. Two days before admission the patient

Address for correspondence: A J Limburg, Dept Internal Medicine, University Hospital, PO Box 30.001.9700 RB Groningen. The Netherlands.

Accepted for publication 11 August 1988 . became nauseous with vomiting. He experienced left sided pain in the chest and became dyspnoeic. The next day he noticed swelling of the face and the dyspnoea became worse. On admission the patient was hypotensive and tachypneic. Extensive subcutaneous emphysema was noted. A chest radiograph showed subcutaneous and mediastinal emphysema and a hydropneumothorax on the left. A chest tube drained a large quantity of purulent fluid and an oesophageal perforation was suspected. A contrast oesophagram showed a gross leak from the distal oesophagus into the left chest. The patient was operated on and a $2 \mathrm{~cm}$ perforation of the oesophagus was visualised $10 \mathrm{~cm}$ above the gastroesophageal junction. Drainage of the area was performed as sole treatment, with the addition of antibiotics and parenteral nutrition.

Two months after operation a contrast oesophagram showed a stenosis, but no leakage and endoscopy revealed a Barrett's oesophagus with the squamocolumnar junction at $25 \mathrm{~cm}$ and at $34 \mathrm{~cm}$, in the area of the perforation, a severe stenosis, which was dilated successfully.

\section{Patient 2}

This 62 year old man was admitted for surgery of his knee. He was known to have had gastro-oesophageal reflux and atypical retrosternal pain for many years. Six years earlier an endoscopy showed a hiatal hernia and an ulceration in the distal oesophagus which was attributed to the use of indomethacin. On admission to the orthopaedic department the patient was using 
naproxen and antacids. At operation a total knee prosthesis was inserted under epidural anaesthesia. One day after operation severe retrosternal pain occurred with progressive dyspnoea and hypotension. Radiological examination showed a right hydropneumothorax. A chest tube drained coffee ground stomach fluid and an oesophageal perforation was suspected. At thoracotomy a small perforation was seen in the distal oesophagus and a suture repair was performed. A contrast oesophagram on the seventh postoperative day showed a small hiatal hernia but no leakage and no stenosis. Endoscopy two and a half months after operation showed a Barrett's oesophagus with two Barrett's ulcers without stenosis. The ulcers finally healed during medical therapy.

\section{Discussion}

Barrett's ulcers are common in Barrett's oesophagus and may be the cause of severe restrosternal pain and upper gastrointestinal haemorrhage. Although perforation as a complication is mentioned in most reviews, the literature refers to only two cases: one presented with a bleeding caused by a penetrating ulcer, which had perforated in a perioesophageal artery, ${ }^{4}$ and in the other patient the diagnosis of an oesophageopleural fistula caused by a perforated Barrett's ulcer was made at autopsy. Within six months we have seen two patients with perforated Barrett's ulcers, who presented with the classic clinical picture of spontaneous oesophageal perforation. One of these patients was known with a Barrett's ulcer, which perforated in spite of treatment with high dose $\mathrm{H}_{2}$ blockers. The other patient was known with gastro-oesophageal reflux disease but Barrett's oesophagus was not recognised for many years. Oesophageal ulcerations in the past were attributed to the ingestion of non-steroidal anti-inflammatory agents, which may indeed have played an important role in the formation of these Barrett's ulcers.

Barrett's oesophagus is increasingly recognised as a frequently occurring, often occult complication of gastroesophageal reflux disease, with an incidence of about $13 \%$ in patients with symptomatic reflux. ${ }^{67}$ This prevalence is higher compared with the results of retrospective endoscopic surveys in the past. The routine use of diagnostic endoscopy has greatly contributed to this increased frequency of diagnosing Barrett's oesophagus and endoscopy has been shown to be superior to radiography for its detection. ${ }^{7}$ With this background we studied the literature concerning spontaneous oesophageal perforation and its possible relation to underlying oesophageal disease. In three large studies a total number of 77 patients with spontaneous oesophageal rupture has been reported. Only seven $(9 \%)$ of these were mentioned to have an underlying oesophageal disorder. ${ }^{.111}$ In these studies oesophageal disease had been ruled out by radiological examination and surgical impression, whereas endoscopic evaluation was not mentioned and probably not done in most patients. Considering the low accuracy of barium studies in detecting Barrett's óesophagus the possibility of a perforated Barrett's ulcer had not been excluded in most of these patients. Therefore a Barrett's ulcer could have played an aetiological role in at least some patients with a spontaneous perforation in a radiologically grossly normal oesophagus.

In conclusion one should be suspicious of an underlying oesophageal disorder in patients who present with a spontaneous oesophageal perforation. Antireflux therapy should be considered in such patients until a Barrett's ulcer has been excluded as the cause of the rupture.

\section{References}

1 Skinner DB. Perforation of the esophagus: spontaneous (Boerhaave's syndrome), traumatic, and following esophagoscopy. In: Sabiston DC Jr, ed. Textbook of surgery. Philadelphia: Saunders, 1986: 749-53.

2 Boerhaave $H$. Atrocis, nec descripti pius, morbi historia: secundum medicac artes leges consciptu, Lugd Bat, Boutesteniana, 1724. Translated in Bull Med Libr Ass 1955; 43: 217.

3 Patton AS, Lawson DW, Shannon JM, Risley FS, Bixby FE. Reevaluation of the Bocrhaave syndrome: a review of fourteen cases. Am J Surg 1979; 137: 56()-5.

4 Borie J, Goldwater C. Columnar cell-lined esophagus: assessment of etiology and treatment. A 22-year experience. J Thorac Cardiovasc Surg 1976; 71: 825-34.

5 Andersson R, Nilsson S. Perforated Barrett's ulcer with esophago-pleural fistula. A case report. Acta Chir Scand 1985; 151: 495-6.

6 Schnell T, Sontag S, Wanner J, et al. Endoscopic screening for Barrett's esophagus, esophageal adenocarcinoma and other mucosal changes in ambulatory subjects with symptomatic gastroesophageal reflux [Abstract]. Gastroenterology 1985; 88: 1576.

7 Winters C Jr, Spurling TJ, Chobanian SJ, et al. Barrett's esophagus: a prevalent, occult complication of gastroesophageal reflux disease. Gastroenterology 1987; 92: 118-24.

8 Abbott OA, Mansour KA, Logan WD Jr, Hatcher CR, Symbas PN. Atraumatic so-called spontaneous rupture of the esophagus. A review of 47 personal cases with comments on a new method of surgical therapy. J Thorac Cardiovasc Surg 1970; 59: 67-82.

9 Michel L, Grillo HC, Malt RA. Operative and nonoperative management of esophageal perforations. Ann Surg 1981; 194: 57-63.

10 Rosoff L, White EJ. Perforation of the esophagus. Am J Surg 1974; 128: 207-14. 